\title{
The Predictive Importance of Selected Protective Factors against Different Types of Antisocial Behavior Manifested by Adolescent Boys and Girls
}

\author{
Ivana Václaviková1, Lenka Selecká1, Slávka Démuthová1, Marek Blatný ${ }^{2}$, Michal Hrdlička ${ }^{3}$ \\ ${ }_{1}^{1}$ Department of Psychology, Faculty of Arts, Ss. Cyril and Methodius University, Trnava, Slovak Republic \\ ${ }^{2}$ Department of Psychology, Faculty of Arts, Masaryk University, Brno, Czech Republic \\ ${ }^{3}$ Department of Paediatric Psychiatry, $2^{\text {nd }}$ Faculty of Medicine, Charles University in Prague and Motol University \\ Hospital, Czech Republic \\ The study aims to identify protective factors against antisocial behavior of adolescents. Data from the \\ SAHA project (The Social and Health Assessment), obtained from a16-year-old juvenile cohort, were \\ used to analyze antisocial behavior of adolescent boys $(N=733)$ and girls $(N=1110)$. Subsequently, \\ levels of the predictive importance of the protective factors of the family environment, school environ- \\ ment, fulfilled leisure time and individual factors were tested through multinomial regression analysis in \\ the groups of boys and girls. Slightly different paths to the absence of antisocial behavior were identified \\ for adolescent boys and girls. Key predictors for adolescent boys with non-problem behavior are prosocial \\ beliefs, prosocial behavior, leisure time, expectations of goal attainment, parental involvement, and teacher \\ support. For adolescent girls, positive school environment, feelings of safety at school, parental warmth, \\ parental supervision, prosocial beliefs, optimistic beliefs, and leisure time contribute to non-problematic \\ behavior.
}

Key words: antisocial behavior, protective factors, adolescence

\section{Introduction}

Adolescence is perceived as a period of increased risk of manifestations of problem behavior (Modecki, 2016). Researchers are increasingly interested in identifying protective factors that reduce the likelihood of antisocial behavior, not only in the absence of risk factors but also in their presence, through a specific interaction between them (Morrison, Brown, D'Incau, O'Farrell, \& Furlong, 2006; Portnoy, Chen, \& Raine, 2013).
Research supports the importance of protective factors such as attachment to parents, social skills, internalized moral beliefs, interaction and engagement in close relations with prosocial peers, and rewarding of prosocial expressions, not only in terms of reducing antisocial behavior and alcohol use but also in relation to lower incidence of depressive symptomatology (Connell, Cook, Aklin, Vanderploeg, \& Brex, 2011; Monahan, Oesterle, Rhew, \& Hawkins, 2014). Protective factors lead to positive developmental manifestations, even when an individual is confronted with risk factors.

Correspondence concerning this article should be addressed to Marek Blatný, Department of Psychology, Faculty of Arts, Masaryk University, Brno, Czech Republic, E-mail: blatny@phil.muni.cz ORCID https://orcid.org/0000-0001-9831-0637

Received June 2, 2019

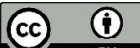


Furthermore, a connection has been identified between these factors and a lower occurrence of problem behavior during pubescence and early adolescence (Morrison et al., 2006; Pollard, Hawkins, \& Arthur, 1999).

The importance of protective factors in relation to antisocial behavior can be studied at the interpersonal level (family, school, and leisure time activities) and at the individual level (intrapersonal context). At the interpersonal level, important factors include relationships with parents and other significant adults (including teachers). The importance of effective parenting in relation to the deviant behavior of adolescents is documented by extensive research (Torrente \& Vazsonyi, 2008). Key parenting methods involve parental support (Ritakallio, Luukkaala, Marttunen, Pelkonen, \& Kaltiala-Heino, 2010), effective communication (Steinberg \& Silk, 2002) and psychological control (Barber, Bean, \& Erickson, 2002). In the school environment, the relationship between the child and the teacher (McCurdy, Mannella, \& Eldridge, 2003) and the overall school climate (McEvoy \& Welker, 2000) are important. During adolescence, peers become more important for fulfilling the need for belonging; numerous studies have demonstrated the harmful effect of peer-to-peer rejection on adolescent development, and this experience is assessed as a risk factor for later maladjustment (Sentse, Lindenberg, Omvlee, Ormel, \& Veenstra, 2010). On the other hand, the experience of acceptance by peers has a positive effect (Ladd \& Burgess, 2001). Furthermore, a child (or an adolescent) may also experience acceptance and success by engaging in extracurricular activities (Mahoney, 2000), especially in highly complex and cooperative ones. Peer social networks created based on shared goals and interests could work as a possible supportive agent.

With regard to personality characteristics, protective factors in the form of prosocial involvement and internalized moral beliefs appear to be highly functional (Kaufmann, Wyman, Forbes-Jones, \& Barry, 2007). Malti and Krettenauer (2013), in a meta-analysis based on 42 studies involving more than 8,000 partici- pants, showed that moral emotions are related to both prosocial and antisocial behavior.

A protective factor may be gender itself (Morrison et al., 2006). Moffitt and Caspi (2001) report the ratio of boys to girls' antisocial behavior as 1.5 to 1 during adolescence. In general, risk factors have a stronger relationship to problem behavior in girls, while protective factors are more relevant for the inhibition of undesirable activities in boys (Monahan et al., 2014).

There is an obvious trend of strengthening research orientation towards protective factors against antisocial behavior (Connell et al., 2011; Monahan et al., 2014; Morrison et al., 2006). However, numerous studies exploring protective factors in relation to the inhibition of antisocial behavior have focused on one or several selected variables. We assume that the simultaneous focus on a wider spectrum of potential antecedents will enable the identification of those that contribute most to the prediction of the extent of antisocial behavior and that specifically have the strongest inhibitory potential against it.

The identification of protective factors for antisocial behavior is undoubtedly more effective when the specifics of those who report this behavior are taken into account. Person-centered approach has the potential to provide a more structured view, and it is important for practical application in the form of interventions or educational programs and psychological counseling (Blatný, Jelínek, \& Hrdlička, 2016). In this way, it is possible to consider whether a certain group of adolescents can be characterized by the simultaneous occurrence of specific behavioral manifestations to create a differentiated profile (Modecki, 2016). We assume that the use of a person-centered approach in the research will allow us to preserve sensitivity to the context of particular expressions and identify their concurrent incidence, characterizing specific types of adolescents depending on the extent and severity of the manifested antisocial behavior.

Studies on this topic (Blatný, Jelínek, \& Osecká, 2009; Vassallo, Smart, Sanson, Dussuyer, \& Victoria, 2002) demonstrate different representations of girls and boys among 
adolescents with non-problem behavior as well as those characterized by a higher degree of antisocial expression. Different extents of the manifestation of antisocial behavior based on gender have been confirmed by the creation of two separate typologies, one for a group of adolescent boys and the second for a group of adolescent girls (Selecká, Václaviková, Blatný, \& Hrdlička, 2017). Despite the fact that, at the basic level, similar predictors for life-long manifestations of antisocial behavior appear to be important for both men and women, some risk and protective factors are identified as more crucial in relation to specific behavioral expressions of boys or girls (Monahan et al., 2014; Torrente \& Vazsonyi, 2008).

Consequently, the simultaneous use of person-centered and variable-centered approaches provides a more comprehensive understanding of the context of protective factors and the extent of adolescent involvement in antisocial behavior.

The main objective of the current study is to identify the most important protective factors while focusing on a wider spectrum of possible antecedents. Thus, the aim is to identify which protective factors contribute most to the prediction of the extent of antisocial behavior.

Furthermore, the current study focuses on the simultaneous examination of the significance of protective factors with regard to the severity of the antisocial behavior in the typologies created (Selecká et al., 2017) separately for adolescent boys and girls. More specifically, the aim is to identify which protective factors are most relevant for the inclusion of adolescent boys in type 1, non-problem behavior (compared to the types exhibiting 2, conduct problems, 3 , conduct problems with drug and alcohol abuse and consequences from formal authorities, and 4, antisocial behavior) and for the inclusion of adolescent girls in type 1, non-problem behavior (compared to type 2 , conduct problems and 3 , antisocial behavior).

\section{Methods}

\section{Sample}

The research was conducted on a representative sample of juveniles from urban areas in the Czech Republic (Prague and 12 regional cities) in three age cohorts (12-year-old, 14year-old and 16-year-old). Participants were selected through the procedure of stratified random sampling (see Blatný, Hrdlicka, Ruchkin, Vermeiren, \& Schwab-Stone, 2006; Blatný et al., 2016).

The results of this study are based on data obtained from the 16-year-old juvenile cohort, which contains data from 1,843 adolescents (733 boys and 1110 girls). This age cohort was chosen because of the most prevalent manifestations of antisocial behavior (e.g., forms of aggressive behavior, drug-related crime) and the assumption of greater personality and behavioral stability (e.g., prosocial behavior, a higher level of internalization of moral beliefs).

Based on the results of the Blatný et al. (2016) studies, we created a typology of antisocial behavior in an earlier study (Selecká et al., 2017). Using a non-hierarchical cluster analysis on SAHA's items, reflecting different manifestations of antisocial behavior separately for groups of boys and girls. The separate computations for the groups of boys and girls led to the formation of different typologies. In the case of boys, four types of antisocial behavior were identified (Table 1).

Table 1 The typology of antisocial behavior in boys

\begin{tabular}{lcc}
\hline Type & $N$ & $\%$ \\
\hline Non-problem behavior & 416 & 56.75 \\
Conduct problems & 188 & 25.65 \\
Conduct problems with drug and alcohol abuse and with & & \\
consequences from formal authorities & 82 & 11.20 \\
Antisocial behavior & 47 & 6.41 \\
\hline
\end{tabular}


Table 2 The typology of antisocial behavior in girls

\begin{tabular}{lcc}
\hline Type & $N$ & $\%$ \\
\hline Non-problem behavior & 682 & 61.44 \\
Conduct problems & 313 & 28.20 \\
Antisocial behavior & 115 & 10.36 \\
\hline
\end{tabular}

In the case of girls, a slightly different typology was created. Conduct problems and conduct problems with current prevalence of alcohol/drug abuse constitute one type, and the result of the cluster analysis is three types of antisocial behavior for girls (Table 2).

\section{Measures}

Social and Health Assessment (SAHA); (Schwab-Stone et al., 1999) is a thematically broad-based questionnaire survey dealing with risk and protective factors in the social development and health of school youth. The questionnaire consists of 65 structured questions divided into 375 items. The questions and scales are divided into two large domains. The first domain consists of questions focused on sources of risk and protective factors, and the second domain is represented by questions on the impacts on behavior and mental health. In the present study, the following scales from SAHA were used:

The Antisocial Behavior Scale $(\alpha=.788)$ identifies conduct problems of varying severity (Schwab-Stone et al., 1999) in the following main domains (subscales): 1) conduct problems/norms violation, 2) property offenses and 3) violent behavior, including items focused on 4) disciplinary and legal consequences of antisocial behavior (disciplinary proceedings at school, arrest). Participants score on a 5-point scale how many times they have been involved in one of the types of antisocial behavior in the last year $(0=$ not at all, $1=$ once, $2=$ twice, $3=$ three to four times, $4=$ five times or more). Item example: "In the last year, how many times did you steal in the store?"

The potential protective factors, based on the SAHA method, were examined as follows:

Conventional Involvement Scales: conven- tional involvement/extracurricular activities $(\alpha=.507)$, leisure time $(\alpha=.411)$. Participants are asked, for example, how many hours per week they spend engaging in particular extracurricular activities or how they spend their free time (e.g., watching $\mathrm{TV}$, reading, ...).

School Environment and Academic Motivation Scales: attachment to school $(\alpha=.813)$, school environment $(\alpha=.720)$, perceived teacher support $(\alpha=.711)$, academic motivation $(\alpha=.577)$. Participants score on a 4-point scale (from "not true at all" to "absolutely true"), for example, if they like going to school, if they feel safe in the school environment, if they perceive teachers as being supportive, and if the education seems to be important for them.

Parenting Scales: parental involvement $(\alpha=$ $.725)$, parental supervision $(\alpha=.718)$, parental warmth $(\alpha=.796)$. Above mentioned scales represent items as follow: "My parents ask me how my life is going.", "My parents want to know, who I am spending time with.", and "My parents are proud of me." Participants score on a 4-point scale (from "never" to "often").

Prosocial Attitudes and Behavior: prosocial beliefs $(\alpha=.816)$, expectations of the future ( $\alpha=.786)$, happiness $(\alpha=.862)$, and prosocial behavior $(\alpha=.598)$. Area of the questionnaire represented by the mentioned scales contains, for example, following items: "How bad is it to steal in a store?", "What are your chances of happy family life?", or "Usually, I share with others.".

\section{Results}

Through a multinomial regression analysis, we tested the predictive importance of selected protective factors such as family environment, school environment, leisure activities, and individual factors leading to the inclusion of an 
individual into a particular type based on manifested antisocial behavior.

Tabachnick et al. (2001) stated that multinomial logistic regression is more robust to violations of assumptions of multivariate normality and equal variance-covariance matrices across groups. On the other hand, multicollinearity can violate the informative value of the results. Therefore, we tested the multicollinearity of the predictors with tolerance and VIF statistics. The predictors have proven not to be biased by multicollinearity.

Model of regression analysis in boys: the predicted values were not significantly different from the values of the analyzed model
(Pearson $=1921.787, p=.994)$, and the model decreased the proportion of unexplained variance significantly $\left(x^{2}=295.654, d f=45\right.$, $p=.000)$. In the group of boys, significant protective factors were identified (Table 3). For inclusion in the group of unproblematic boys, the most prominent predictor is the acquisition of prosocial beliefs. Further, the incidence of prosocial behavior, engaging in extracurricular activities and positive expectations for the future are identified as being significant predictors. Last but not least - parental involvement and supervision, as well as teacher support, contribute to the inclusion in the group without problem behavior.

Table 3 Results of a multinomial logistic regression analysis of a group of non-problem adolescent boys against the groups of boys with antisocial behavior

\begin{tabular}{lccccc}
\hline 1 vs 2 & $B(S E)$ & $P$ & Lower & Odds Ratio & Upper \\
\hline Conventional involvement & $.094(0.40)$ & .017 & 1.017 & 1.099 & 1.187 \\
Teacher support & $-.088(0.034)$ & .008 & .857 & .915 & .978 \\
Parental supervision & $.068(0.026)$ & .010 & 1.017 & 1.070 & 1.126 \\
Prosocial beliefs & $-.147(0.023)$ & .000 & .825 & .863 & .903 \\
\hline 1 vs 3 & $B(S E)$ & $P$ & Lower & Odds Ratio & Upper \\
\hline Leisure time & $.082(0.038)$ & .032 & 1.007 & 1.086 & 1.170 \\
Prosocial beliefs & $-.192(0.029)$ & .000 & .779 & .825 & .874 \\
\hline 1 vs 4 & $B(S E)$ & $P$ & Lower & Odds Ratio & Upper \\
\hline Leisure time & $.136(0.064)$ & .035 & 1.010 & 1.146 & 1.300 \\
Prosocial behavior & $.317(0.137)$ & .021 & 1.049 & 1.373 & 1.797 \\
Parental involvement & $-.216(0.101)$ & .032 & .661 & .806 & .982 \\
Future expectations & $-.140(0.067)$ & .037 & .763 & .870 & .991 \\
Prosocial beliefs & $-.369(0.044)$ & .000 & .634 & .691 & .754 \\
\hline
\end{tabular}

Note. $R^{2}=.340$ (Cox \& Snell), $R^{2}=.385$ (Nagelkerke)

Table 4 Results of a multinomial logistic regression analysis of a group of non-problem adolescent girls against the groups of girls with conduct problems

\begin{tabular}{lccccc}
\hline 1 vs 2 & $B(S E)$ & $P$ & Lower & Odds Ratio & Upper \\
\hline Leisure time & $.081(0.036)$ & .026 & 1.010 & 1.084 & 1.164 \\
Prosocial beliefs & $-.242(0.027)$ & .000 & .745 & .785 & .828 \\
\hline 1 vs 3 & $B(S E)$ & $P$ & Lower & Odds Ratio & Upper \\
\hline School attachment & $-.067(.032)$ & .035 & .879 & .935 & .995 \\
School environment & $.066(.030)$ & .028 & 1.007 & 1.068 & 1.132 \\
Safety at school & $.058(0.026)$ & .028 & 1.006 & 1.060 & 1.116 \\
Parental supervision & $.076(0.019)$ & .000 & 1.039 & 1.079 & 1.120 \\
Parental warmth & $-.073(0.033)$ & .026 & .871 & .929 & .991 \\
Happiness & $-.077(0.040)$ & .050 & .856 & .926 & 1.000 \\
Prosocial beliefs & $-.124(0.019)$ & .000 & .852 & .884 & .917 \\
\hline
\end{tabular}

Note. $R^{2}=.219$ (Cox \& Snell), $R^{2}=.263$ (Nagelkerke) 
In the group of girls, the regression analysis model also appears to be appropriate (Pearson $=2203.902, p=.157$ ), and the model significantly reduced the proportion of unexplained variance $\left(x^{2}=268.135, d f=30\right.$, $p=.000)$. In the group of girls, some different protective factors were identified (Table 4). Here, the school climate or the feeling of safety in school play significant role as predictors for the inclusion in the group of unproblematic girls. Further, parental supervision and perceived expressions of parental warmth are important predictors. In terms of the individual, prosocial beliefs remain in the position of a prominent predictor.

\section{Discussion}

The importance of a separate approach to analyzing conduct problems among adolescent boys and girls was discussed in a paper that aimed to verify the suitability of a typology based on the extent and severity of this behavior (Selecká et al., 2017). Because the typologies for adolescent boys and girls proved to be valid, we proceeded to analyze the protective factors against antisocial behavior separately for each particular type.

In general, for inclusion in the group of unproblematic boys, individual factors appear to be the most important ones. Specifically, the most prominent predictor is the acquisition of prosocial beliefs, in agreement with Kaufmann et al. (2007). The extent of moral internalization distinguishes non-problem boys from all other types. Therefore, it is crucial in terms of the development of (im)moral behavioral tendencies (Hoffman, 2000; Malti \& Latzko, 2010).

The incidence of prosocial behavior, where higher scores mean a lower likelihood of belonging to the non-problematic group of boys rather than the group that exhibits antisocial behavior, may appear paradoxical. However, the prosocial behavior of an individual may be aimed at a member of his/her own social group (Sobotková, Blatný, \& Hrdlička, 2007) and may potentially have antisocial manifestations. This may be how a group of adolescents evaluates itself as a prosocial group.
Boys who do not exhibit problem behavior are more likely to engage in extracurricular activities, where they may develop their potential and have less free time to spend on unfocused activities. In accordance with the abovementioned findings, Mahoney (2000) notes the relationship between participation in extracurricular activities organized by the school and a lower probability of early school dropout or arrest among high-risk boys and girls. Social relationships that are associated with participation in such activities play an important role in inhibiting antisocial behaviors. Even highrisk youth can benefit from the social contacts that extracurricular activities may involve. These include values that are consistent with the values of society and consequently lead to a reduction of antisocial behavior.

With regard to assuming goal achievement (e.g., academic success, future work success and personal fulfillment), boys with a higher level of positive expectations for the future are most likely to be in the first type (without conduct problems) when compared to the group of boys exhibiting a significant extent of antisocial behavior. Future expectations are perceived as fundamental, a developmental change occurs in the effort to adapt to the demands of the future (Seginer, 2008). Non-problematic adolescents assume the least difficulty in fulfilling developmental tasks and achieving future successes. This finding supports the identified association of risk behaviors and future expectations (Sipsma, Ickovics, Lin, \& Kershaw, 2012).

In the interpersonal context, the parent-child relationship appears to be crucial. For inclusion in the group of unproblematic boys, parental involvement is particularly important (Torrente \& Vazsonyi, 2008). Additionally, parental control is identified as a significant factor. Specifically, boys belonging to the non-problem behavior type do not receive parental control to such an extent. We can consider whether a certain level of rebellion against adult authority and an effort not to comply with requirements is the adolescent's response to a stricter educational style or whether increased parental control follows committed offenses. 
In terms of the school environment, the position of the teacher is significant. In boys, perceived teacher support decreases with manifestations of antisocial behavior. This finding can be explained in several ways: antisocial behavior may be the result of a sensitively felt support deficit; alternately, due to the problem behavior of the adolescent, the teacher may provide little favor.

Girls' inclusion in the non-problem behavior type compared with the group with more pronounced antisocial expression takes a slightly different path than that of boys. It appears that environmental factors (the school climate or the feeling of safety in school) play a more important role in the development of girls in a socially desirable way. Because these factors can be considered interconnected, this result also reflects the emotional accent in the form of a positive relationship with the school environment. The unproblematic group of girls exhibits more positive emotions in relation to school, associated with a lower degree of negative evaluations of the school environment. It can be explained in two ways: antisocial behavior may be conditioned by a negative school environment, or the school environment may be experienced as more unfavorable as a result of perceived problems at school.

For the inclusion of girls in the unproblematic group, the importance of parenting is confirmed. An emotional relationship with parents is crucial, especially perceived expressions of parental warmth. These conclusions are supported by Lorincová (2014), who evaluates parental warmth as a protective factor against mental disorders in general and aggressive behavioral tendencies in particular. A lack of support and warmth can result not only in antisocial behavior (Peiser \& Heaven, 1996) but also in depressive manifestations (Ritakallio et al., 2010). Although the importance of the family gradually decreases during adolescence, social support from parents consistently appears to be most effective in preventing the development of depressive symptomatology. According to some studies (e.g., Garnefski, 2000), girls are more vulnerable to a lack of social support. Among them, peers and significant others could be subjectively even more important for fulfilling their needs.

While parental supervision (Formoso, Gonzales, \& Aiken, 2000) and effective communication (Barber et al., 2002) are reported as significant factors for healthy adolescent development, excessive parental control can lead to inclusion in the antisocial girls' group. The question remains whether increased parental supervision is followed by defiant behavior and adolescent girls, through negative behavior, build their own position to find independence or whether this involves a more intense reaction of parents to behavioral changes and occasional fluctuations related to the development period.

We can confirm that the level of internalized moral beliefs is a prominent predictor in terms of the individual. The stronger prosocial beliefs are, the more likely it is that a particular girl will belong to a non-problem behavior type. We can conclude that a set of internalized beliefs about how a person should behave and which behavioral acts are inappropriate or even reprehensible may represent an inhibitory factor for antisocial impulses (Hoffman, 2000; Malti \& Latzko, 2010). As Malti and Krettenauer (2013) state, the degree of moral emotion in adolescents represents an important predictor of prosocial and antisocial behavior. The personality context may be a key because personality traits, agreeableness, and conscientiousness predict the degree of moral emotions achieved (Krettenauer, Asendorpf, \& Nunner-Winkler, 2013).

A specific aspect of the typology of adolescent girls involves subjectively perceived feelings of happiness. As noted by Cook et al. (2015), depression appears to be comorbid with manifestations of antisocial behavior more often in girls than in boys. Thus, feelings of happiness are perceived as opposed to depression and could potentially be considered a protective factor against antisocial expressions.

\section{Limitations and Implications}

The main limitation of this research is the use of a research design based exclusively on self- 
evaluation corresponding with the serious disadvantage of the possible tendency to alleviate existing antisocial behavior by adolescents themselves or to present false increases under the influence of conformity.

The creation of the types of adolescent boys and girls based on reported manifestations of antisocial behavior and subsequently identified factors leading to inclusion in particular types suggest further possibilities for research as well as potential implications for practice. In terms of research, there is an urgent challenge to conduct longitudinal studies that consider not only the numerous risk and protective factors of antisocial behavior but also a sufficient range of their potential internalized and externalized expressions. In terms of practice, key emphasis should be placed on strengthening resources that are effective in inhibiting undesirable activities, such as providing emotional warmth and social support, recognizing the importance of moral beliefs gained at an early age and the process of their internalization, and the ability of the individual to develop his/her potential and experience success. Interventions targeted along this line and implemented by professionals could compensate, to a certain extent, for any potential family deficiencies. Additionally, gender-specific prevention programs (Blatný et al., 2006) may be more effective than nonspecific programs given the different typologies of boys and girls.

\section{Conclusions}

The differentiation of individual types based on the type and intensity of behavioral expressions allows us to obtain a more detailed understanding of conduct problems. Further analysis can lead to a more precise way of identifying predictors that increase the likelihood of individual inclusion in a certain type, namely, the "non-problem behavior" type vs. the type with a high incidence of antisocial expression.

Additionally, on the basis of previous analyses conducted by the authors of the study (Blatný et al., 2016) that suggested an unequal representation of girls and boys in different types, we implemented the typology for both groups separately. The results confirm the purpose of this step, not only because of the creation of different typologies but also because the results point to differences in the significance of individual predictors (protective factors) leading to inclusion in the non-problematic type for adolescent boys and girls. Based on the identification of variables that are relevant in this respect, more precise testing of their significance will be undertaken in further studies.

\section{Acknowledgements}

Publication has been supported by the project "Risk behavior in adolescence, the incidence and influencing factors" of the Scientific grant agency of the Ministry of Education of the Slovak Republic (ME SR) and of Slovak Academy of Sciences (SAS) no. VEGA 1/0042/17.

\section{References}

Barber, B. K., Bean, R. L., \& Erickson, L. D. (2002) Expanding the study and understanding of psychological control. In B. K. Barber (Ed.), Intrusive parenting: How psychological control affects children and adolescent (pp. 263-289). Washington, DC: American Psychological Association. doi: 10.1037/10422-009

Blatný, M., Hrdlicka, M., Ruchkin, V., Vermeiren, R., \& Schwab-Stone, M. (2006). Antisocial involvement, use of substances, and sexual behaviors among urban youth in the Czech Republic. Studia Psychologica, 48(2), 107-124.

Blatný, M., Jelínek, M., \& Hrdlička, M. (2016). Typologie antisociálního chování ve střední adolescenci a její vztah k užívání návykových látek (Typology of antisocial behavior in middle adolescence and its relation to substance use). Česká a Slovenská Psychiatrie, 112(3), 107-113.

Blatný, M., Jelínek, M., \& Osecká, T. (2009). How does personality develop over the lifecourse: Results of the Brno longitudinal study on life-span development. Social development. New York, NY: Nova Science Publishers.

Connell, C. M., Cook, E. C., Aklin, W. M., Vanderploeg, J. J., \& Brex, R. A. (2011). Risk and protective factors associated with patterns of antisocial behavior among nonmetropolitan adolescents. Ag- 
gressive Behavior, 37(1), 98-106. doi: 10.1002/ ab.20370

Cook, E. C., Pflieger, J. C., Connell, A. M., \& Connell, C. M. (2015). Do specific transitional patterns of antisocial behavior during adolescence increase risk for problems in young adulthood? Journal of Abnormal Child Psychology, 43(1), 95-106. doi: 10.1007/s10802-014-9880-y

Formoso, D., Gonzales, N. A., \& Aiken, L. S. (2000) Family conflict and children's internalizing and externalizing behavior: Protective factors. American Journal of Community Psychology, 28(2), 175199. doi: $10.1023 / \mathrm{A}: 1005135217449$

Garnefski, N. (2000). Age differences in depressive symptoms, antisocial behavior, and negative perceptions of family, school, and peers among adolescents. Journal of the American Academy of Child \& Adolescent Psychiatry, 39(9), 1175-1181. doi: 10.1097/00004583-200009000-00018

Hoffman, M. L. (2000). Empathy and moral development. Cambridge, England: Cambridge University Press.

Kaufmann, D. R., Wyman, P. A., Forbes-Jones, E. L., \& Barry, J. (2007). Prosocial involvement and antisocial peer affiliations as predictors of behavior problems in urban adolescents: Main effects and moderating effects. Journal of Community Psychology, 35(4), 417-434. doi: 10.1002/jcop.20156

Krettenauer, T., Asendorpf, J. B., \& Nunner-Winkler, G. (2013). Moral emotion attributions and personality traits as long-term predictors of antisocial conduct in early adulthood: Findings from a 20year longitudinal study. International Journal of Behavioral Development, 37(3), 192-201. doi: 10.1177/0165025412472409

Ladd, G., \& Burgess, K. B. (2001). Do relational risks and protective factors moderate the linkages between childhood aggression and early psychological and school adjustment? Child Development 72(5), 1579-1601. doi: 10.1111/1467-8624.00366

Lorincová, T. (2014). Vzt'ahová väzba a agresívne prejavy v období mladšej dospelosti - "čiastkové výsledky". Psychologie a Jeji Kontexty, 5(1), 2938.

Mahoney, J. L. (2000). School extracurricular activity participation as a moderator in the development of antisocial patterns. Child Development, 71(2), 502-516. doi:10.1111/1467-8624.00160

Malti, T., \& Krettenauer, T. (2013). The relation of moral emotion attributions to prosocial and antisocial behavior: A meta-analysis. Child Development, 84(2), 397-412. doi:10.1111/j.1467-8624.2012. 01851.x

Malti, T., \& Latzko, B. (2010). Children's moral emotions and moral cognition: Towards an integrative perspective. New Directions for Child and Adolescent Development, 2010(129), 1-10. doi: $10.1002 / \mathrm{cd} .272$

McCurdy, B. L., Mannella, M. C., \& Eldridge, N. (2003). Positive behavior support in urban schools: Can we prevent the escalation of antisocial behavior? Journal of Positive Behavior Interventions, 5(3) 158-170. doi: 10.1177/10983007030050030501

McEvoy, A., \& Welker, R. (2000). Antisocial behavior, academic failure, and school climate: A critical review. Journal of Emotional and Behavioral Disorders, 8(3), 130-140. doi:10.1177/ 106342660000800301

Modecki, K. L. (2016). Do risks matter? Variable and person-centered approaches to adolescents' problem behavior. Journal of Applied Developmental Psychology, 42, 8-20. doi:10.1016/j.appdev. 2015.11.001

Moffitt, T. E., \& Caspi, A. (2001). Childhood predictors differentiate life-course persistent and adolescence-limited antisocial pathways among males and females. Development and Psychopathology, 13(2), 355-375. doi: 10.1017/ S0954579401002097

Monahan, K. C., Oesterle, S., Rhew, I., \& Hawkins, J. D. (2014). The relation between risk and protective factors for problem behaviors and depressive symptoms, antisocial behavior, and alcohol use in adolescence. Journal of Community Psychology, 42(5), 621-638. doi:10.1002/ cop.21642

Morrison, G. M., Brown, M., D'Incau, B., O'Farrell, S. L., \& Furlong, M. J. (2006). Understanding resilience in educational trajectories: Implications for protective possibilities. Psychology in the Schools, 43(1), 19-31. doi: 10.1002/pits.20126

Peiser, N. C., \& Heaven, P. C. L. (1996). Family influences on self-reported delinquency among high school students. Journal of Adolescence, 19(6), 557-568. doi:10.1006/jado.1996.0054

Pollard, J. A., Hawkins, J. D., \& Arthur, M. W. (1999). Risk and protection: Are both necessary to understand diverse behavioral outcomes in adolescence? Social Work Research, 23(3), 145-158. doi: $10.1093 / \mathrm{swr} / 23.3 .145$

Portnoy, J., Chen, F. R., \& Raine, A. (2013). Biological protective factors for antisocial and criminal behavior. Journal of Criminal Justice, 41(5), 292299. doi:10.1016/j.jcrimjus.2013.06.018

Ritakallio, M., Luukkaala, T., Marttunen, M., Pelkonen, M., \& Kaltiala-Heino, R. (2010). Comorbidity between depression and antisocial behaviour in middle adolescence: The role of perceived social support. Nordic Journal of Psychiatry, 64(3), 164171. doi:10.3109/08039480903264911 
Schwab-Stone, M., Chen, C., Greenberger, E., Silver, D., Lichtman, J., \& Voyce, C. (1999). No safe haven II: The effects of violence exposure on urban youth. Journal of the American Academy of Child \& Adolescent Psychiatry, 38(4), 359-367. doi: $10.1097 / 00004583-199904000-00007$

Seginer, R. (2008). Future orientation in times of threat and challenge: How resilient adolescents construct their future. International Journal of Behavioral Development, 32(4), 272-282. doi: 10.1177/ 0165025408090970

Selecká, L., Václaviková, I., Blatný, M., \& Hrdlička, M. (2017). Typológia antisociálneho správania: Špecifiká prejavov adolescentných chlapcov a dievčat vo vzt’ahu $\mathrm{k}$ rizikovému sexuálnemu správaniu. Česká a Slovenská Psychiatrie, 113(6), 258-267.

Sentse, M., Lindenberg, S., Omvlee, A., Ormel, J., \& Veenstra, R. (2010). Rejection and acceptance across contexts: Parents and peers as risks and buffers for early adolescent psychopathology. The TRAILS study. Journal of Abnormal Child Psychology, 38(1), 119-130. doi: 10.1007/s10802-0099351-z

Sipsma, H. L., Ickovics, J. R., Lin, H., \& Kershaw, T. S. (2012). Future expectations among adolescents:
A latent class analysis. American Journal of Community Psychology, 50(1-2), 169-181. doi:10.1007/ s10464-011-9487-1

Sobotková, V., Blatný, M., \& Hrdlička, M. (2007). Antisociální chování dospívajících a vztahy s vrstevníky: Rád se $s$ tebou podělím o ukradené cédéčko. Sborník Prací Filozofické Fakulty Brněnské Univerzity, Řada Psychologická, 55(P11), 65-72.

Steinberg, L., \& Silk, J. S. (2002). Parenting adolescents. In M. Bornstein (Ed.), Handbook of parenting: Volume 1: Children and parenting (pp. 103-133). Mahwah: Erlbaum.

Tabachnick, B. G., Fidell, L. S., \& Osterlind, S. J. (2001). Using multivariate statistics. US, Allyn and Bacon Boston.

Torrente, G., \& Vazsonyi, A. T. (2008). The salience of the family in antisocial and delinquent behaviors among Spanish adolescents. The Journal of Genetic Psychology, 169(2), 187-197. doi: 10.3200/GNTP.169.2.187-198

Vassallo, S., Smart, D., Sanson, A., Dussuyer, I., \& Victoria, C. P. (2002). Patterns and precursors of adolescent antisocial behaviour: The first report. Melbourne: Crime Prevention Victoria. 